\title{
CUIDAD O INTERGERACIONAL COM O IDOSO: autonomia do idoso e presença do cuidador
}

\author{
Gisela Catal di F L ORE Sa, Zulmira N ewlands BORGES ${ }^{b}$, M aria de L ourdes DE NA RDIN -BU D Óc, \\ Fernanda Carlise M AT T ION I
}

\begin{abstract}
RESUMO
Objetivou-se descrever e interpretar a autonomia e a presença como determinantes e significantes do cuidado intergeracional com o idoso. Pesquisa qualitativa, etnográfica, com dados coletados por entrevista e observação participante. U tilizou-se análise de conteúdo para análise dos dados. Os sujeitos foram dez idosos e seus respectivos cuidadores. E mergiram duas categorias temáticas: a autonomia como determinante do cuidado e a presença como significante do cuidado. A relação dos idosos com seus cuidadores está baseada na garantia da preservação da sua autonomia, a qual os faz se sentirem cuidados. A presença significou cuidado para a maioria dos idosos, determinada pela disponibilidade e por estar perto, o que representou segurança. Dessa forma, o cuidado intergeracional com o idoso deve ser norteado pelo respeito e pela preservação da sua autonomia, considerando-se, ainda, a importância da presença condicionada ao respeito à totalidade e à complexidade das pessoas aos seus modos de vida e valores culturais.
\end{abstract}

D escritores: Cuidados de enfermagem. Envelhecimento. I doso. Cultura.

\section{RESUMEN}

El estudio tuvo como objetivo describir e inter pretar la autonomía y la presencia como determinantes y significantes del cuidado intergeneracional con el anciano. E s una investigación cualitativa, etnográfica, con datos recolectados por entrevista y observación partici pante. Seutilizó un análisis de contenido para el análisis de los datos. L os sujetos fueron diez ancianos y sus respectiv os cuidador es. E mergier on dos categorías temáticas: la autonomía como deter minante del cuidado y la presencia como significante del cuidado. L a relación de los ancianos con sus cuidadores está basada en la garantía de la preservación de su autonomía, la cual hace que se sientan cuidados. L a presencia significó cuidado para la mayoría de los ancianos, determinada por la disponibilidad y por estar cerca, lo que representó seguridad. E I cuidado intergeneracional con el anciano debe ser orientado por el respecto y por la preservación de su autonomía, considerándose, todavía, la importancia de la presencia condicionada al respecto a la totalidad y a la complejidad de las personas a sus modos de vida y valores culturales.

Descriptores: A tención de enfermería. E nvejecimiento. Anciano. Cultura.

Título: Cuidado intergeneracional con el anciano: autonomía del anciano y presencia del cuidador.

\section{ABST RACT}

This study aimed to describe and inter pret autonomy and presence as deter minants and signifiers of intergenerational care to the elderly. It is a qualitative and ethnogra phic research, with data collected through interviews and participant observation. The subjects w ere ten elderly and their respective caregivers. T wo thematic categories emerged: autonomy as determinant of careand presence as signifier of care The relation of elderly with their caregivers is based on ensuring their autonomy's preservation, which makes them feel cared. P resence meant care for most seniors, determined by availability and being near, which represented security. Thus, intergenerational care to the elderly should be guided by respect for and preservation of their autonomy, considering al so the importance of the presence conditioned on respect of people's totality and complexity to their lifestyles and cultural values.

D escriptors: N ursing care. A ging. A ged. Culture

$T$ itle: Intergenerational care with elderly: autonomy of the elderly and presence of caregiver.

\footnotetext{
a M estre em Enfermagem, Coordenadora do Curso de Pós-Graduação em G erontologia: ênfase em Gerontologia Social da Faculdade Integrada de Santa M aria (F ISM A), Coordenadora A djunta e D ocente do Curso de G raduação em Enfermagem da FI SM A, E nfermeira da Secretaria Estadual de Saúde / 4a Coordenadoria Regional de Saúde, Santa M aria, Rio Grande do Sul, Brasil.

b Pós-D outora em E ducação, Professora Associada II do D epartamento de Ciências Sociais, do Programa de Pós-Graduação em Enfermagem (PPG E nf) e do Programa de Pós-G raduação em Ciências Sociais da U niversidade Federal de Santa M aria (U F SM ), Líder do G rupo de Estudos e Pesquisas em Cultura, Gênero e Saúde da U F SM, Santa M aria, Rio Grande do Sul, Brasil.

c Doutora em Enfermagem, Professora Associada do Departamento de Enfermagem e do PPGEnf da UFSM, Vice-Líder do Grupo de Pesquisa Cuidado, Saúde e E nfermagem da U F SM, Santa M aria, Rio G rande do Sul, Brasil.

- M estranda em Saúde Pública da E scola N acional de Saúde Pública Sérgio A rouca da F undação O swaldo Cruz, Bolsista CAPES, T écnica em Saúde E cologia H umana da Coordenação E stadual da Estratégia Saúde da F amília da Secretaria E stadual de Saúde do Rio G rande do Sul, Brasil.
} 


\section{INT RODUÇÃO}

0 envelhecimento populacional é um fenômeno mundial que tem gerado reflexão e discussão no meio acadêmico, nos serviços de saúde, nas instâncias gover namentais e não gover namentais. E sse fenômeno demonstra uma questão demográfica, que exige reflexão, planejamento e conhecimento do cuidado com o idoso, requerendo transformações nas ações de planejamento e prática de cuidado, para assim oportunizar qualidade de vida aos idosos. N este estudo, entende-se qualidade de vida como a percepção do indivíduo de sua posição na vida, no contexto da cultura e do sistema de valores nos quais ele vive e em relação aos seus objetivos, expectativas, padrões e preocupações(1).

Compreender e vivenciar o envelhecimento populacional, de forma positiva ou negativa, está relacionado ao ol har das outras gerações, isto é, à forma como as demais gerações interpretam e vivenciam o processo de envelhecer. $M$ as também está atrelado ao modo como os idosos se percebem e constroem o seu envel hecer ${ }^{(2)}$.

É evidente a relevância em desenvolver estudos relacionados ao envel hecimento populacional, considerando os quadros mundial e nacional que apresentam uma realidade epidemiológica e social com uma demanda social caracterizada pela presença dos idosos, no cotidiano de vida de todas as gerações ${ }^{(3)}$.

Para refletir acerca dessa temática é necessário compreender que o envelhecimento é um processo complexo, geralmente associado a doenças, incapacidades, dependência e perda da autonomia. Todavia, o cuidado ao idoso precisa estar consolidado no respeito à sua autonomia, a qual significa ter capacidade de deliberar a respeito de seus objetivos próprios e de ter atitudes em direção a eles(4). No entanto, algumas famílias e instituições restringem indevidamente a participação dos idosos na tomada de decisões.

O Estatuto do I doso destaca a preservação da autonomia ao relacioná-la com o direito ao respeito, que consiste na inviolabilidade e na integridade física, psíquica e moral ${ }^{(5)}$. Sabe-se que o respeito à preservação da autonomia do idoso é incipiente na prática, na implementação e na execução das políticas públicas brasileiras nos serviços de saúde - visto que os mesmos recebem 0 atendimento fragmentado, no qual se estabelece uma dependência deles com os profissionais de saúde, pois a to- mada de decisão em relação a cuidados, tratamento e adesão às condutas, em geral, é realizada pelos profissionais. Também se percebe na prática profissional que a escuta e o saber popular não raras vezes são desconsiderados, no que se refere ao planejamento de ações de cuidado que norteiem a qualidade de vida dos idosos. Pensar e vivenciar 0 envel hecimento com qualidade de vida pressupõe pensar, planejar e executar ações que objetivem a preservação da autonomia das pessoas idosas.

O bserva-se que a qualidade de vida desse grupo social pressupõe a presença como condição fundamental para a prática do cuidado intergeracional com o idoso. A presença, como cuidado, caracteriza-se pelo convívio entre as pessoas, por meio do qual se aprende a cuidar.

Considerando o envelhecimento populacional, é relevante 0 avanço nas pesquisas em enfermagem, de modo que partam da realidade social, reflitam e construam conhecimento científico para que haja a transformação na sociedade. Essa área da saúde tem como questão central o cuidado, que é singular e complexo e tem despertado 0 interesse das diversas áreas do conhecimento, porque, de alguma forma, todas as pessoas são cuidadoras, sejam elas profissionais ou não na área da saúde ${ }^{(6)}$.

E ste estudo, fruto de uma dissertação de M estrado(7), voltou-se para o cuidado popular dos idosos, especificamente, para o cuidado familiar, que implica o cuidado intergeracional. As concepções e as estratégias do cuidado, nessas circunstâncias informais, podem contribuir com as reflexões a respeito do cuidado na enfermagem e proporcionar novos diálogos e novas interações entre cuidadores formais e informais. Objetivou-se, nesta pesquisa, descrever e interpretar a autonomia e a presença como determinantes e significantes do cuidado intergeracional com o idoso.

\section{MÉT ODO}

T rata-se de um estudo qualitativo, sendo escolhido o método etnográfico. 0 ponto de partida desse método é a inter ação entre o pesquisador e os sujeitos da pesquisa, em que se dá ênfase ao cotidiano e ao subjetivo. Tal procedimento permite uma aproximação com o contexto, oportunizando uma interpretação da complexidade social e a riqueza de olhares, bem como a observação das especificidades da comunidade. A abordagem etno- 
gráfica foca-se na ideia de que os comportamentos humanos só podem ser devidamente compreendidos e explicados se for tomado como referência o contexto social onde os sujeitos pesquisados atuam, exigindo uma atenção especial aos discursos e aos atos do cotidiano, que as entrevistas por si só não contemplam. $\mathrm{Na}$ pesquisa de campo de cunho etnográfico, deseja-se entender o que "está sendo dito" pelos sujeitos de pesquisa(8).

Participaram da pesquisa, idosos e seus cuidadores, moradores em região de abrangência de uma U nidade de Saúde da Família (USF) em município do interior do Rio Grande do Sul. Para inclusão dos idosos seguiram-se os critérios: ter 60 anos ou mais, dispor-se a participar da pesquisa, conviver com outras gerações e ter capacidade de comunicação, isto é, conseguir ouvir e responder adequadamente às questões. Para inclusão dos cuidadores, os critérios foram conviver com os idosos e ser identificado pelos idosos como cuidador principal. Os dez idosos e os dez cuidadores de outras gerações foram incluídos no estudo após o conhecimento do território e da realidade local da realização da pesquisa. Todos os idosos convidados a participar da pesquisa aceitaram, contudo uma filha cuidadora não aceitou. Assim, nesse caso não foi possível incluir a idosa no estudo. 0 número de participantes seguiu o critério de saturação dos dados ${ }^{(9)}$.

Como técnicas de coleta de dados foram utilizadas a observação participante e a entrevista semiestruturada ${ }^{(9)}$. A observação participante ocorreu nas casas dos idosos e dos seus cuidadores, nos grupos de portadores de hipertensão arterial, nas ruas, em um mercado da comunidade, em velório e em culto religioso. Foram surgindo convites para a pesquisadora conviver com os sujeitos da pesquisa a partir do primeiro encontro com os idosos, o que oportunizou a convivência com os mesmos nos seus cotidianos. As entrevistas com os idosos e seus cuidadores ocorreram durante a observação participante, no período de fevereiro a maio de 2008. Cada entrevista teve a duração aproximada de uma hora. As mesmas ocorreram nas casas dos sujeitos da pesquisa, sendo que algumas foram com o idoso e seu cuidador juntos e, outras, só com um deles. A análise dos dados sustentouse na análise de conteúdo(10).

Seguindo os princípios éticos de uma pesquisa com seres humanos, previstos na Resolução 196/ 96 do Conselho N acional de Saúde ${ }^{(11)}$, foi li- do e entregue o T ermo de Consentimento Livre e Esclarecido, em duas vias, uma para o sujeito da pesquisa e outra para o pesquisador. Foi também solicitada a gravação das entrevistas. A coleta de dados iniciou após aprovação do projeto de pesquisa pelo Comitê de Ética em Pesquisa da instituição à qual o projeto está vinculado, que tem 0 Certificado de A presentação para A preciação É tica (CAE E) número 0001.0.243.000-08.

\section{RESULTADOS E DISCUSSÃO}

\section{Caracterização dos sujeitos da pesquisa}

Os idosos deste estudo estavam nas seguintes faixas etárias: de 60 a 69 anos, três mulheres; de 70 a 79 anos, cinco mulheres; e de 80 anos e mais, dois homens. Percebe-se que no gênero masculino a faixa etária é a partir dos 80 anos, fato que não ocorre com as idosas, pois a maior concentração destas está nas idades entre 70 a 79 anos, destacando-se 0 gênero feminino entre as pessoas com 60 anos e mais. Todos os idosos apresentavam alguma doença e agravo não transmissível, como hipertensão arterial, diabetes, osteoporose, artrose, depressão, entre outras. M esmo com essa realidade, os sujeitos possuíam facilidade de comunicação e de compreensão, o que possibilitou a inter ação. Ficou evidente, também, a possibilidade do exercício de autonomia, pois, embora necessitassem de cuidadores, podiam deliberar e tomar atitudes em relação a suas vidas.

Dos dez cuidadores, sete são mulheres e três homens, distribuídos por idade: menor de 18 anos, uma mulher; de 20 a 25 anos, uma mulher e um homem; de 30 a 39 anos, dois homens e duas muIheres; de 40 a 49 anos, duas mulheres; e de 50 a 59 anos, uma mulher.

Observa-se que, entre todos os cuidadores, a faixa etária prevalente é de pessoas entre 30 e 39 anos, seguida da faixa etária de 40 a 49 anos, junto com a faixa etária de 20 a 25 anos. Pode-se concluir que os cuidadores dos idosos são pessoas na maioria adultas e que o gênero feminino é prevalente no cuidado intergeracional. Os cuidadores são filhos, filhas, noras, netas e neto.

$\mathrm{Na}$ geração composta pelos filhos e noras foram observados diferentes motivos que levam as pessoas a cuidar. Para al gumas cuidadoras, o cuidado aparece como uma consequência da trajetória e da história familiar de cuidados preceden- 
tes das idosas em relação a filhos e netas, sobressaindo a ideia de reciprocidade, em que a mesma tem como mecanismo central a solidariedade, defendendo uma nova moral, baseada no respeito mútuo e na generosidade recíproca. A vida social exige obrigações e disciplina, mas ela repousa também sobre a troca, a reciprocidade e as relações contratuais ${ }^{(12,13)}$

Para al gumas filhas, a prática do cuidado ocorreu por falta de alternativa, pois nas suas famílias não existia outra pessoa com disponibilidade para cuidar. As filhas cuidadoras das idosas apresentavam, em algumas situações, sobrecarga gerada pelos diferentes papéis sociais impostos. E m algumas mulheres cuidadoras observou-se que sobressaíram sentimentos de responsabilidade e obrigação, no sentido de cumprir as expectativas sociais do cuidado.

Já os homens que cuidavam das suas mães abordaram o cuidado como escolha própria ou como escolha da família, mas não como sobrecarga no cotidiano das suas vidas. Os mesmos cuidavam porque tinham disponibilidade, isto é, nas suas vidas existia tempo para cuidar, pois eram donos de seu próprio negócio ou trabalhavam em empresa familiar.

0 gênero determinou as atribuições do cuidado para todas as gerações, em que se destacou o cuidado feminino, com características próprias deste gênero, como disponibilidade, percepção e organização. As mulheres experienciam a subvalorização do seu trabalho tanto formal quanto doméstico, esse historicamente tido como feminino ${ }^{(14)}$. N este estudo, as cuidadoras eram do lar e estudantes, dedicando-se ao cuidado da casa e das pessoas de todas as gerações. Já os homens eram trabal hadores formais.

\section{A autonomia como determinante do cuidado}

A autonomia foi um tema de destaque para todas as gerações. Contudo o significado de ter autonomia diferenciou-se entre os idosos e as outras gerações.

Para os idosos, a autonomia representa fator fundamental para sua qualidade de vida e preservação da dignidade. A maioria dos idosos, nesta pesquisa, tem a autonomia preservada e, quando sente sua perda, relaciona ao desrespeito às suas decisões, bem como à dependência econômica.
E m algumas situações, a presença constante e a imposição de decisões em suas vidas, impedindo a livre deliberação a respeito de fatos do cotidiano, impossibilitaram sua autonomia. Isso pode ser constatado em uma das famílias, na qual a idosa identificou como sua cuidadora principal uma filha que reside próximo à sua casa. $\mathrm{A}$ idosa demonstrou 0 desejo de mudar de residência para sair de perto dos filhos, pois referiu não ter autonomia perto deles.

E u quero sair daqui. Quero morar noutro lugar onde eu possa decidir minha vida. J á achei um lugar onde minhas amigas estão. D aí eles não vão decidir minha vida (Rosa).

A necessidade de autodeter minação, decidindo sobre as situações mais simples do cotidiano, implica um elemento importante e estruturante na qualidade de vida, pois o ser humano só é sujeito quando está livre, quando se autodetermina e toma consciência de sua liberdade. Para cuidar é importante que 0 cuidador respeite 0 direito de decisão do sujeito cuidado. Ao considerar as múltiplas possibilidades do ser cuidado, a liberdade inerente a todo ser humano e suas singularidades, o cuidador estará respeitando a autonomia como direito social e legal ${ }^{(15)}$.

A falta de autonomia também pode estar vinculada à dependência física, pela necessidade do cuidado intergeracional, nos casos de incapacidade funcional. I sso pode ser constatado, quando a idosa relata a situação em que ocorreu uma cirurgia que a obrigou a ficar imobilizada, dependendo da neta:

F iquei três meses na cama. E la [ a neta] me lavava, me ajudava a tomar banho. M e sentia ruim, porque não podia me virar sozinha (Vera).

Para manter a autonomia e a independência, outra idosa demonstrou a importância de estar em movimento, pois sempre foi encontrada cozinhando ou limpando a casa. Queixava-se de dores nos ossos, em função da osteoporose, que a deixava limitada para fazer tudo que fazia quando era mais jovem:

[ ...] é a parte mais braba, porque quando a gente é nova, a gente trabalha, tem aquela disposição, não sente dor. Chega certa idade a gente vai trabalhar, dói aqui, dói ali (L eda). 
Portanto a falta de autonomia, as situações de dependência e de limitações dos idosos foram consideradas problemas para todos. A consequência de alguma enfermidade que leva à dependência foi fator que interferia negativamente na saúde e na qualidade de vida. Outro estudo com idosos também vinculou saúde com independência, capacidade para fazer as coisas, trabalhar, poder ir e vir, mesmo apresentando doenças crônicas ${ }^{(16)}$.

Além dessas situações, os idosos referiram a sustentação econômica e a ajuda financeira, que influenciavam a preservação, ou não, da autonomia. Elas foram relacionadas ao cuidado intergeracional com o idoso, no sentido de suprir as necessidades. Ilustrando essa situação, uma idosa, quando perguntada sobre a prática do cuidado intergeracional, respondeu:

Tem meu filho que me sustenta (I nácia).

E $m$ alguns casos, a ajuda financeira foi referida como condicionada ao cuidador não ter que suprir financeiramente a sua família nuclear, com a seguinte fala:

U m filho meu que não tem filho pequeno, ajuda com dinheiro (Lílian).

N este estudo, o tema emergiu nos contextos familiares em que as idosas não recebiam aposentadoria, ou quando a renda familiar era a aposentadoria do idoso ou de cônjuge já falecido. Essa dependência foi identificada como falta de autonomia, quando as idosas ficam esperando ajuda dos filhos. Por outro lado, também foi considerada como preservação da autonomia, quando relacionada à melhoria da qualidade de vida, inclusive oportunizando a elas decidirem o que fazer com 0 dinheiro recebido.

A pesar da realidade brasileira demonstrar que os idosos são, com frequência, responsáveis pelo sustento das gerações mais jovens, observou-se que, quando isso é experienciado pelas idosas, existe uma geração intermediária - os fiIhos -, que oportunizam às idosas a responsabilidade pela sustentação econômica das netas. Essa situação foi observada quando as mulheres idosas chefiam as famílias.

A troca ocorrida entre cuidadores e idosos faz-se presente, sobretudo, quando há sustento e apoio financeiro por parte dos mais novos. São ati- tudes de retribuição ao cuidado recebido, pela presença ou por meio de atitudes de suprimento das necessidades básicas, tais como alimentação e higiene.

A queles que se identificaram autônomos, demonstraram sentir-se valorizados pelas outras gerações. Para eles, não ter autonomia reflete na qualidade de vida, significando não serem reconhecidos na família como pessoas capacitadas para fazer escolhas, não se sentindo tratados com afeto e incluídos socialmente.

Os idosos que preservaram a autonomia demonstraram que ser autônomo os faz sentirem-se com a dignidade preservada. A firmaram que a autonomia pode ser vivenciada no cotidiano, mesmo quando há alguma dependência. Assim, no cuidado intergeracional com o idoso, deve-se, sobretudo, colaborar na sua preservação, respeitando escolhas e oportunizando a liberdade de agir, mesmo diante da dependência.

Observou-se que a tomada de decisões dos idosos acerca das suas vidas foi associada a viver bem, apesar de outras limitações orgânicas naturais do processo de envelhecimento e de alguns idosos dependerem financeiramente de seus fiIhos. I dentificaram-se al guns contextos em que estar doente não deixava 0 idoso sem autonomia, mas a privação de decidir sua vida o fazia sentirse desvalorizado e excluído da família e da sociedade. Em outro estudo, concluiu-se que partilhar as decisões é um caminho para praticar a autono$\operatorname{mia}^{(17) .}$

Para os cuidadores dos idosos, a autonomia foi relacionada ao cuidado com significados diferenciados, visto que os homens cuidadores das idosas relacionaram a autonomia como condicionante para eles praticarem o cuidado com suas mães.

Para as mulheres cuidadoras, a autonomia foi destacada como fundamental para a qualidade de vida delas e das idosas. Os idosos em situação de dependência em relação à família são prejudicados pela diminuição do tempo disponível das mulheres cuidarem de seus familiares. I sso é muito importante, quando o cuidado na família é entendido como presença.

\section{A presença como significante do cuidado}

A presença no cuidado foi destacada como indispensável para praticá-lo e foi relacionada à dis- 
ponibilidade como particularidade cultural atribuída ao gênero feminino. Os homens continuam priorizando o trabalho, e a disponibilidade para 0 cuidado está relacionada ao tipo de trabal ho que exercem e às condições de saúde do idoso. 0 fato de idosos e cuidadores residirem juntos ou muito próximos facilitou o cuidado. A distância geográfica de alguns filhos foi considerada pelos idosos um fator que impossibilitava o cuidado.

A presença significou cuidado, como estar disponível, dar remédios e controlar seus horários de administração. M orar perto, para alguns, é fator significante de cuidado, pois torna o cuidador mais disponível. D eslocar-se até onde está o idoso significou cuidado e ficou subentendida a valorização do idoso pelas outras gerações. 0 cuidado como significante de presença está relacionado a dar resposta às necessidades humanas, considerando que é fundamental estar junto do ser cuidado para suprir algumas delas. Cuidado, por meio da presença, está condicionado ao respeito à totalidade e à complexidade das pessoas, aos seus modos de vida e valores culturais:

E u só não gosto de ficar sozinha [ ...]. T enho maior horror de ficar sozinha. Os filhos me cuidam, quando eu tiver alguma coisa eles me atendem. L evam no médico. Q uase todos os dias um ou outro está aqui. F iquei 12 dias no hospital. Daí um filho ia posar num dia, noutra noiteia a neta (Vera).

A presença como significante de cuidado entrelaçou-se ao significado do cuidado materno como diferencial no cuidado, bem como a responsabilização e o compromisso de cuidar do idoso ser de um cuidador principal, que é identificado pela família. A disponibilidade é considerada condição para cuidar, como foi relatado por um filho cuidador da mãe idosa, que trabalha no mercado, em casa próxima. N esta fala, a presença foi relacionada à autonomia:

E u fico junto da mãe $N$ ão a deixo só porque tem que estar junto para cuidar, se eu trabal hasse fora não daria para cuidar. Tem que proporcionar que ela secuide (Sérgio).

Observou-se que o cuidado exige a formação de uma rede, a qual é construída por diversas gerações. D essa maneira, cuidar pode ser uma experiência compartilhada, na qual os vínculos afe- tivos se fortalecem. Percebeu-se que a presença significou segurança, fator relevante para a sensação de ser cuidado.

0 ser humano é um ser social e, portanto, 0 estabel ecimento de vínculos no seu mundo afetivo é fundamental. Essa potencialidade do ser humano realiza-se rosto a rosto, isto é, no espaço temporal dos seres humanos ${ }^{(15)}$. A partir disso, cuidar sugere presença, na qual o respeito às diversidades, às potencialidades, às especificidades e à liberdade de tomar decisões condiciona a construção de relações intergeracionais e de cuidado intergeracional com uma atitude humanizada e ética.

A dimensão das relações entre as pessoas humanas tem 0 diálogo e 0 amor como categorias fundamentais da existência humana ${ }^{(15)}$. Se o cuidado é condição de sobrevivência humana com dignidade, quando é considerado como uma atitude amorosa, torna-se uma dádiva e uma dívida; uma troca que, de acordo com as particularidades culturais, se constrói nas relações de cuidado(12). N esse sentido, na construção de relações de cuidado, deve-se considerar que estar junto é imprescindível, desde que essa presença seja embasada no respeito ao outro e às particularidades culturais, no afeto e no relativismo.

Neste estudo, as idosas demonstraram que são cuidadoras intergeracionais, cuidando de fiIhos e netos. Percebeu-se que o cuidado oportunizava ao cuidador e ao ser cuidado a construção de relações de solidariedade, as quais favoreciam a valorização familiar e social dos idosos e o convívio intergeracional nas famílias como oportunidade de fortalecer vínculos afetivos, caracterizando a presença como determinante de cuidado.

0 cuidado intergeracional com o idoso pode ser uma experiência prazerosa, ou não, dependendo das relações entre as pessoas, nas quais os significados atribuídos ao idoso e ao cuidado influenciam as atitudes de todas as gerações.

\section{CONSIDERAÇÕES FINAIS}

Os resultados desta pesquisa evidenciam que a autonomia e a presença são elementos importantes quando se reflete acerca do cuidado intergeracional com o idoso. 0 tema preservação da autonomia deve ser pensado e incorporado na prática do cuidado, da mesma forma que a presença como possibilidade de estar perto. 
Conclui-se também que a presença constante na família não é necessariamente uma manifestação de cuidado e pode, inclusive, representar falta de cuidado com o idoso. N ascemos e morremos necessitando de cuidado, mas a qualidade do cuidado dependerá do respeito às especificidades culturais do grupo social em que ele é exercido, constatando-se que o mesmo é intergeracional.

Este estudo possibilitou constatar a relevância em conhecer a realidade social dos idosos e seus cuidadores e de fortalecimento da rede de cuidados. Essa rede ocorre por meio da aproximação entre trabalhadores de saúde e a comunidade, considerando-se as particularidades culturais dos sujeitos cuidados.

Sugere-se que a prática de enfermagem seja pautada pelo aproveitamento dos espaços de aproximação com o idoso e seu cuidador, a fim de que sejam momentos de reconhecimento do contexto das pessoas idosas e seus cuidadores, de troca de saberes, ações que qualificarão o cuidado.

Trabalhar com a dependência sob o ol har do idoso - colocando-se horizontalidade na relação enfermeiro-idoso, em que a enfermagem tenha 0 conhecimento científico gerontológico e o idoso seja respeitado com seu saber e experiência de vida - poderá construir uma relação de confiança e um vínculo entre cuidador e ser cuidado que seja mais eficaz.

A principal limitação desta pesquisa, por tratar-se de etnografia, é a impossibilidade de generalização.

\section{REFERÊ NCIAS}

1 World Health Organization. WHOQOL and spirituality, religiousness and personal beliefs (SRPB): report on W HO Consultation. G eneva; 1998.

2 Peixoto CE. Família e envelhecimento. Rio de Janeiro: FGV; 2004.

3 Papaléo N etto M . 0 estudo da vel hice no século XX: histórico, definição do campo e termos básicos. In: Freitas EV, Py L, N eri AL, Cançado FAX, Doll J, Gorzoni $M L$, organizadores. T ratado de geriatria e gerontologia. Rio de Janeiro: G uanabara Koogan; 2006. p. 2-12.

$4 \mathrm{G}$ oldin JR. Bioética e envel hecimento. In: F reitas EV, Py L, Neri AL, Cançado FAX, D oll J, G orzoni M L, organizadores. T ratado de geriatria egerontologia. Rio de Janeiro: G uanabara Koogan; 2002. p. 85-90.

5 M inistério da Saúde (BR). Lei № 10.741, de 10 de outubro de 2003: dispõe sobre o Estatuto do I doso e dá outras providências. Brasília (DF ); 2003.

6 Brondani CM, Beuter M. A vivência do cuidado no contexto da inter nação domiciliar. Rev $\mathrm{G}$ aúcha Enferm. 2009;30(2):206-13.

7 F lores GC. Eu cuido dela e ela me cuida: um estudo qual itativo sobre o cuidado interger acional com o idoso [ dissertação] . Santa M aria: U niversidade F ederal de Santa M aria; 2008.

8 Fonseca C. Q uando cada caso não é um caso: pesquisa etnog ráfica em educação. Rev Bras E duc. 1999;10: 58-78.

9 Víctora CG, Knauth D R, H assen M NA. Pesquisa qualitativa em saúde: uma introdução ao tema. Por to Alegre: Tomo; 2000.

10 Bardin L. A nálise de conteúdo. Lisboa: E dições 70; 1977.

11 M inistério da Saúde (BR), Consel ho Nacional de Saúde. Resolução 196, de 10 de outubro de 1996: diretrizes e normas regulamentadoras de pesquisa envolvendo seres humanos. Brasília (D F); 1996.

12 M auss M . Sociologia e antropologia. São Paulo: Cosac N aify; 2003.

13 A Imeida SG P, G ermano R M . A teoria da dádiva e o cuidar em enfermagem. Rev $G$ aúcha E nferm. 2009; 30(2):338-42.

14 Budó M LD. Cuidando e sendo cuidado: um modelo cultural de suporte à saúde em comunidade rural de descendentes de imigrantes italianos [ disser tação] . Santa M aria: U niversidade Federal Santa M aria; 1994.

15 Roselló FT . Antroplogia del cuidar. M adrid: M AP FRE; 2005.

16 Pires ZRS, Silva M J. Autonomia e capacidade decisória dos idosos de baixa renda: uma problemática a ser considerada na saúde do idoso. Rev Eletrônica E nferm [ I nternet] . 2001;3(2). D isponível em: http:/ / www.revistas.ufg.br/ index.php/ fen/ issue/ view/ 73. 
17 Lima CA, Tocantins F R. N ecessidades de saúde do idoso: perspectivas para a enfermagem. Rev Bras Enferm. 2009;62(3):367-73.

E ndereço da autora / Dirección del autor / Author's address:

$M$ aria de $L$ ourdes Denardin Budó

Rua A ppel, 800, ap. 208

97015-030, Santa M aria, RS

E-mail:Lourdesdenardin@gmail.com
Recebido em: 01/ 03/ 2010

A provado em: 27/ 07/ 2010 